Dinamika Teknik Mesin 8 (2018) 8-13
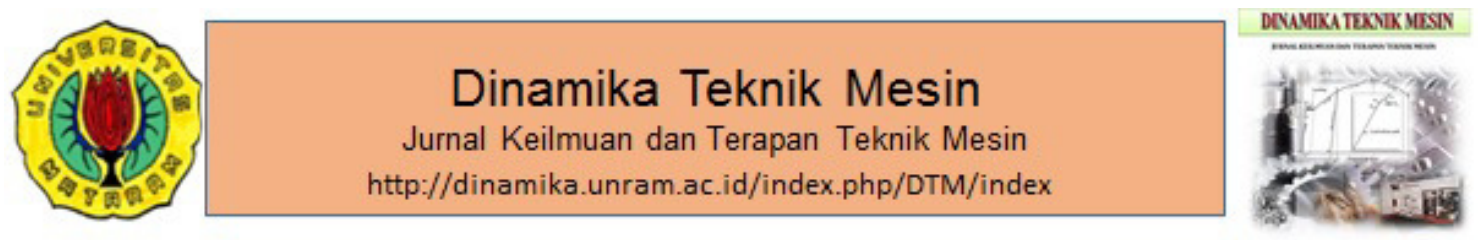

\title{
Analisis emisi gas buang dan daya sepeda motor pada volume silinder diperkecil
}

\author{
I.M. Mara*, I.M.A. Sayoga, I.G.N.K. Yudhyadi, I.M. Nuarsa
}

Teknik Mesin Fakultas Teknik Universitas MataramJln. Majapahit No.62 Mataram Nusa Tenggara

Barat Kode Pos: 83125Telp. (0370) 636087; 636126; ext 128 Fax (0370) 636087

*Email : made.mara@ymail.com

ARTICLE INFO

Article History:

Received 25 July 2017

Accepted 30 September 2017

Available online 1 January 2018

\section{Keywords:}

Volume displacement

Fuel consumption

Exhaust emissions

\section{ABSTRACT}

This research aims to determine the effect of variations diameter pistons on exhaust emissions and fuel consumption. This research used a gasoline engine single-cylinder four-stroke with variations in cylinder volume $100 \mathrm{cc}, 90 \mathrm{cc}, 60 \mathrm{cc}$ and engine rotation 1500 rpm, $2500 \mathrm{rpm}, 3500 \mathrm{rpm}, 4500 \mathrm{rpm}, 6000 \mathrm{rpm}$. Data was collected in transmission $N, 1,2,3$, and 4 each of the three repetitions for each round engine rotation, using a gas analyzer 2400 ultra 4/5 IM Hanatech brand for exhaust emission of $\mathrm{CO}$ and $\mathrm{HC}$. Based on data analysis, it can be concluded that with decreasing diameter of piston up to $60 \mathrm{cc}$ can reduce exhaust emissions, especially $\mathrm{CO}, \mathrm{HC}$ and fuel consumption. The highest HC exhaust emissions was in $100 \mathrm{cC}$ cylinder volume that is equal to $514.33 \mathrm{ppm}$ while the lowest $\mathrm{HC}$ emissions obtained in $60 \mathrm{cc}$ cylinder volume at $49.67 \mathrm{ppm}$. The highest $\mathrm{CO}$ emission was obtained on 100 cc cylinder by $4.64 \%$ volume, while the lowest CO emission was obtained on $60 \mathrm{cc}$ cylinder by $0.31 \%$ volume. The highest $\mathrm{CO}_{2}$ emissions obtained in $60 \mathrm{cC}$ cylinder amounted to $17.60 \%$ volume, while the lowest $\mathrm{CO}_{2}$ emission obtained at $100 \mathrm{cc}$ cylinder amounted to $8.37 \%$ volume, and the highest fuel consumption obtained in $100 \mathrm{cc}$ cylinder at $0.65 \mathrm{~kg} / \mathrm{h}$, and the lowest fuel consumption obtained in $60 \mathrm{cc}$ cylinder by 0.06 $\mathrm{kg} / \mathrm{h}$.

\section{PENDAHULUAN}

Polusi udara telah lama menjadi wacana yang ramai dibicarakan.Seiring bertambahnya jumlah orang yang menggunakan kendaraan bermotor, membuat lingkungan semakin dipenuhi dengan udara-udara yang tidak sehat.Belum lagi berdirinya pabrik-pabrik besar yang cenderung mengabaikan factor pencemaran udara dan banyaknya masyarakat yang merokok, semakin menambah jumlah polusi udara di lingkungan kita.

Khusus untuk daerah NTB Menurut data dari PLT Diskop UMKM NTB jumlah kendaraan saat ini mencapai 959.000 unit hampir mendekati satu juta unit terdiri dari roda empat sebanyak 78.349 unit,kendaraan roda tiga 1072 unit 
kemudian roda dua yang mencapai 880.000 lebih (Kartiko, 2013 ).

Dengan jumlah sepeda yang terus meningkat dari tahun ke tahun, tidak dapat dihindari peningkatan jumlah emisi gas buang yang dihasilkan.Hal ini sudah selayaknya ditangani dengan usaha pembatasan dan pengendalian secara serius dan berkesinambungan. Usaha penurunan tingkat emisi gas buang pada kendaraan bukanlah suatu yang gampang dilakukan.

Emisi kendaran bermotor mengandung gas karbon dioksida $\left(\mathrm{CO}_{2}\right)$, nitrogen oksida (NOx), karbon monoksida (CO), unburn hydro carbon ( $\mathrm{uHC}$ ), dan partikel lain yang berdampak negatif pada manusia ataupun lingkungan bila melebihi ambang konsentrasi tertentu (sayoga, 2001). Berdasarkan uraian tersebut di atas maka dalam penelitian ini pengurangan emisi yang buang dilakukan dengan memperkecil volume silinder kendaraan. Namun demikian penurunan volume silinder akan menurunkan daya mesin.

Tujuan dari penelitian ini adalah untuk menurunkan tingkat emisi gas buang dan menganalisis daya mesin sepeda motor Honda Supra X 100cc.

\section{Emisi Gas Buang}

Gas buang adalah gas sisa pembakaran bahan bakar dalam silinder baik yang terbakar secara sempurna ataupun tidak. Gas buang motor bensin umumnya terdiri dari gas tidak beracun $\mathrm{N}_{2}$ (nitrogen), $\mathrm{CO}_{2}$, (karbon dioksida) dan $\mathrm{H}_{2} \mathrm{O}$ (uap air). Sedangkan gas beracunberupa NOx (nitrogen oksida), HC (hidro karbon), dan $\mathrm{CO}$ (karbon monoksida).

Volume yang terbentuk akibat pergerakan piston dari titik mati bawah munuju titik mati atas (dan sebaliknya). Volume silinder (volume displacement) ini dapat dihitung dengan menggunakan rumus volume tabung dengan satuan cc (Wijoyo, 2008).

$V d=\frac{\pi \times d^{2} \times l \times z}{4}$

Dimana $V d$ adalah volume displacement $\left(\mathrm{cm}^{3}\right), d$ menyatakan diameter silinder (cm), I menunjukan panjang langkah $(\mathrm{cm})$ dan $z$ adalah jumlah silinder.

\section{Daya Efektif $(\mathrm{Ne})$}

Besarnya daya efektif $(\mathrm{Ne})$ akan tergantung dari besarnya torsi dan putaran yang terjadi. Hal ini dapat dilihat dari persamaan berikut (Arismunandar, 1988):
$N e=\frac{T x n}{716,2}$

Di mana $T$ adala torsi (kgf.m), $n$ menyatakan putaran mesin (rpm).

\section{Konsumsi Bahan Bakar}

Fuel consumption merupakan ukuran pemakaian bahan bakar yang digunakan untuk menjalankan mesin dalam suatu periode waktu tertentu, dan biasanya diukur dalam satuan berat bahan bakar per satuan waktu. Besarnya FC dapat dihitung dengan persamaan:

$F C=\frac{b}{t} \times v_{f} \times \frac{3600}{1.000 .000}$

Dimana $F C$ adalah fuel consumption (konsumsi bahan bakar, $\mathrm{kg} / \mathrm{jam}), \quad b$ adalah volume pemakaian bahan bakar, (ml), sedangkan $t$ menyatakan waktu yang digunakan untuk mengkonsumsi bahan bakar, (s) dan $\gamma_{f}$ adalah berat spesifik bahan bakar, $\left(\mathrm{kg} / \mathrm{m}^{3}\right)$.

\section{METODE PENELITIAN \\ Alat dan Bahan}

Adapun alat yang digunakan dalam penelitian ini yaitu Honda Supra X 100 cc, Gas Analyzer, Tachometer dan Stopwatch. Sedangkan bahan yang digunakan berupa bahan bakar premium, oli Shell HSX, lem treebone dan lain-lain.

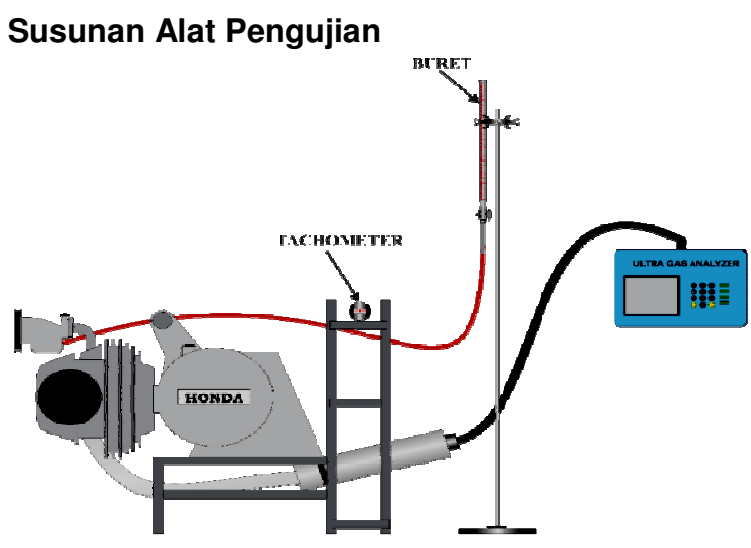

Gambar 1. Susunan alat pengujian. 


\section{HASIL DAN PEMBAHASAN}

\section{Emisi Gas Karbon Monoksida (CO)}

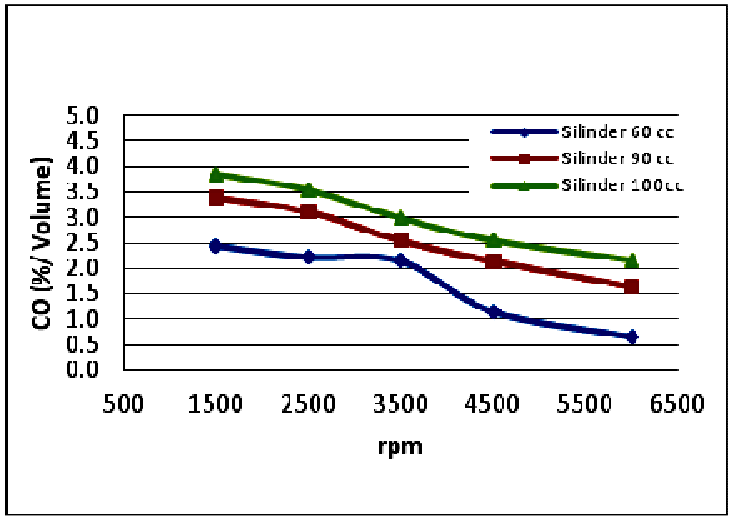

Gambar 2. Kadar emisi CO terhadap putaran pada berbagai variasi volume silinder piston transmisi normal.

Berdasarkan gambar 2, 3 dan 4, tampak emisi $\mathrm{CO}$ semakin turun seiring meningkatnya putaran mesin, pada piston $\varnothing 50 \mathrm{~mm}$, emisi CO tertinggi pada putaran $1500 \mathrm{rpm}$ transmisi 1 sebesar 4,64\%, sedangkan emisi CO terendah ditunjukan pada gambar 4.dengan nilai sebesar $0,31 \%$ terdapat pada silinder piston $60 \mathrm{cc}$ pada putran $6000 \mathrm{rpm}$ transmisi 4. Pada tingkat transmisi 1 dan putaran $1500 \mathrm{rpm}$ rata-rata emisi CO mengalami peningkatan, karena beban yang terjadi lebih besar dibandingkan dengan transmisi yang lain.

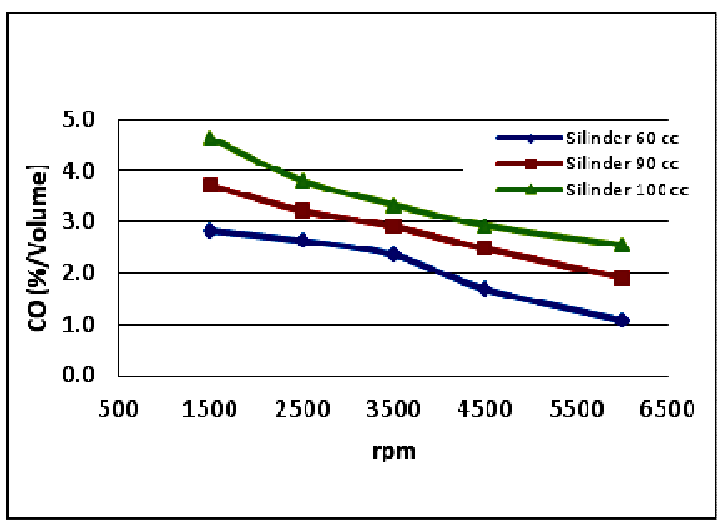

Gambar 3. Kadar emisi CO terhadap putaran pada berbagai variasi volume silinder piston transmisi 1

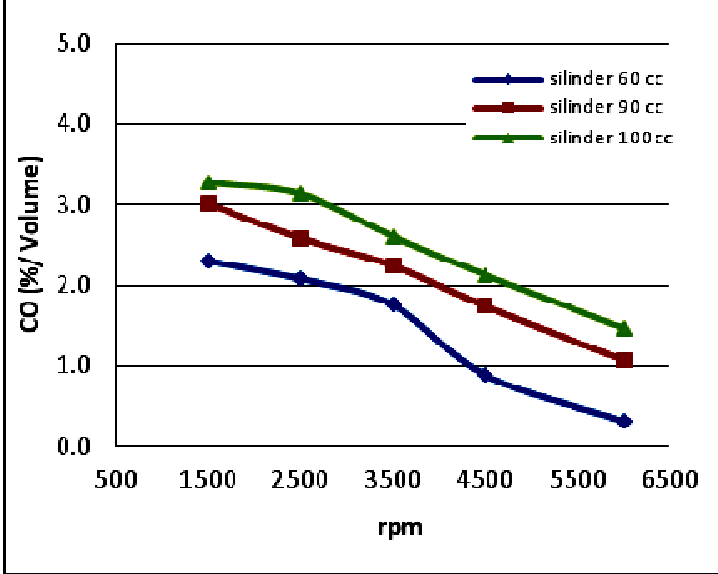

Gambar 4. Kadar emisi CO terhadap putaran pada berbagai variasi volume silinder piston transmisi 4.

\section{Emisi Gas Hidro Karbon (HC)}

Mengacu pada keputusan MNLH No.05/08/2006 mengenai Ambang Batas (Standar) Emisi Gas Buang Kendaraan Bermotor yang menyatakan bahwa batas emisi $\mathrm{CO}$ yang diizinkan sebesar $5,5 \%$ volume, silinder piston 60 cc menghasilkan emisi $\mathrm{CO}$ yang lebih rendah dibandingkan standar. Dengan nilai lamda $\lambda=0,95$ dan gas $\mathrm{CO}_{2}$ yang keluar tinggi dengan nilai $17,60 \%$ menunjukkan bahwa pembakaran yang terjadi pada ruang bakar lebih sempurna.

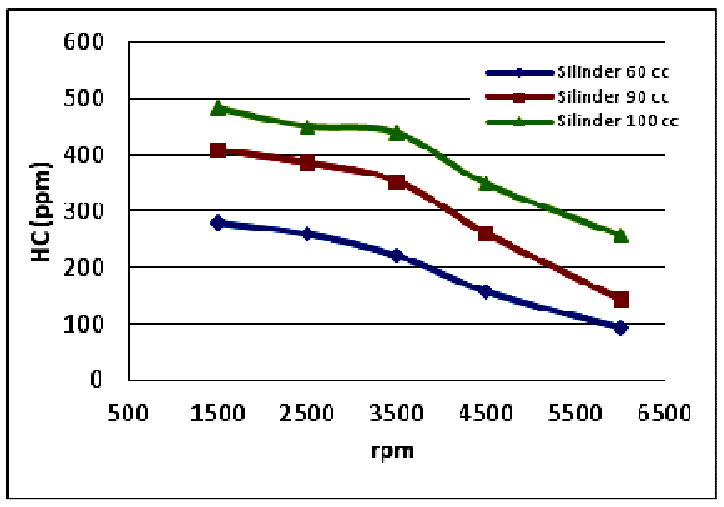

Gambar 5. Kadar emisi HC terhadap putaran pada berbagai variasi diameter piston pada transmisi normal 


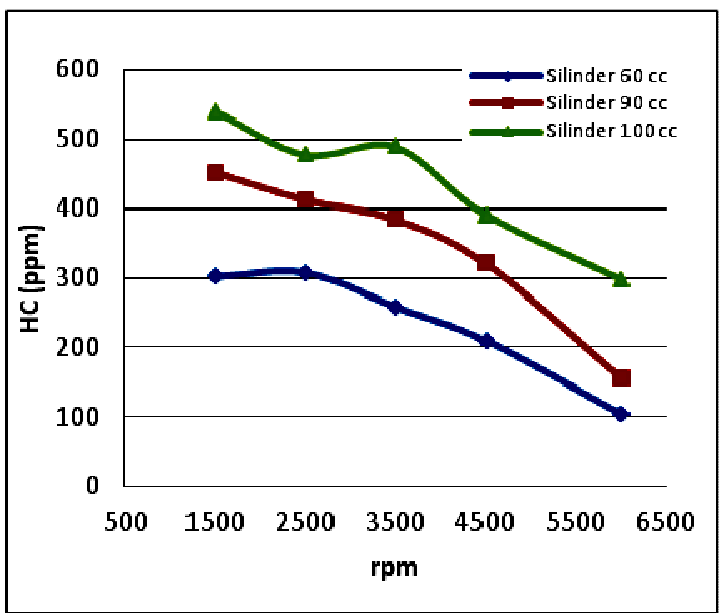

Gambar 6. Kadar emisi HC terhadap putaran pada berbagai variasi diameter piston pada transmisi1

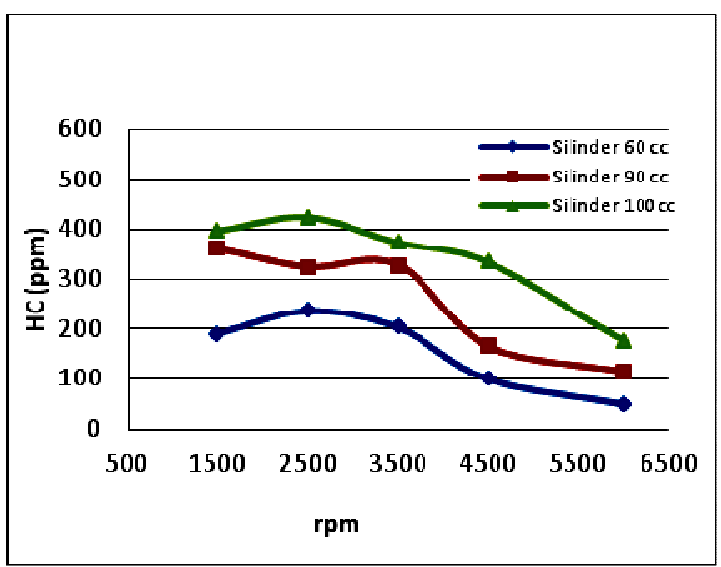

Gambar 7. Kadar emisi HC terhadap putaran pada berbagai variasi diameter piston pada transmisi 4

Gambar 5, 6,dan 7 menunjukkan emisi HC terendah dengan nilai $\mathrm{HC}$ sebesar 49,67 ppm pada putaran $6000 \mathrm{rpm}$ pada silinder piston $60 \mathrm{cc}$ tingkat transmisi 4 . Sedangkan untuk nilai $\mathrm{HC}$ paling tinggi ditunjukkan pada gambar 6 dengan nilai HC sebesar $514,33 \mathrm{ppm}$ tingkat transmisi 1 pada putaran $1500 \mathrm{rpm}$ pada silinder piston 100 cc. Mengacu pada keputusan MNLH No.05/08/2006 mengenai Ambang Batas (Standar) Emisi Gas Buang Kendaraan Bermotor yang menyatakan bahwa batas emisi $\mathrm{HC}$ yang diizinkan sebesar 2400 ppm, silinder piston $60 \mathrm{cc}$ menghasilkan emisi HC yang lebih rendah dibandingkan dengan standar Anonimous (2016).

Pada silinder piston $60 \mathrm{cc}$ emisi $\mathrm{HC}$ yang dihasilkan lebih rendah dibandingkan dengan silinder piston $100 \mathrm{cc}$ dan $90 \mathrm{cc}$. Hal ini disebabkan karena silinder piston 60 cc menghisap bahan bakar dan udara yang lebih sedikit sehingga busi dapat membakar bahan bakar dan udara secara merata sehingga emisi HC dapat berkurang akibat pembakaran yang sempurna.

\section{Emisi Gas Karbon Dioksida $\left(\mathrm{CO}_{2}\right)$}

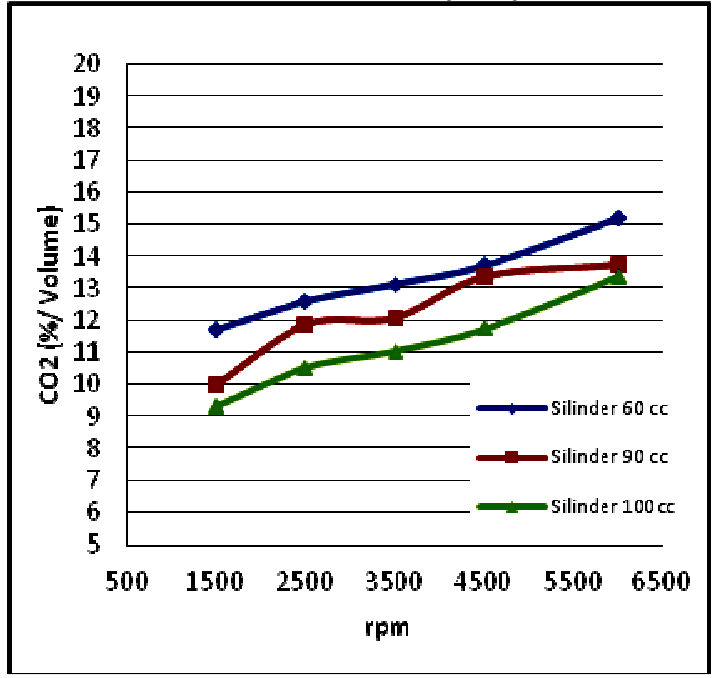

Gambar 8. Kadar emisi $\mathrm{CO}_{2}$ terhadap putaran pada berbagai variasi diameter piston pada transmisi normal

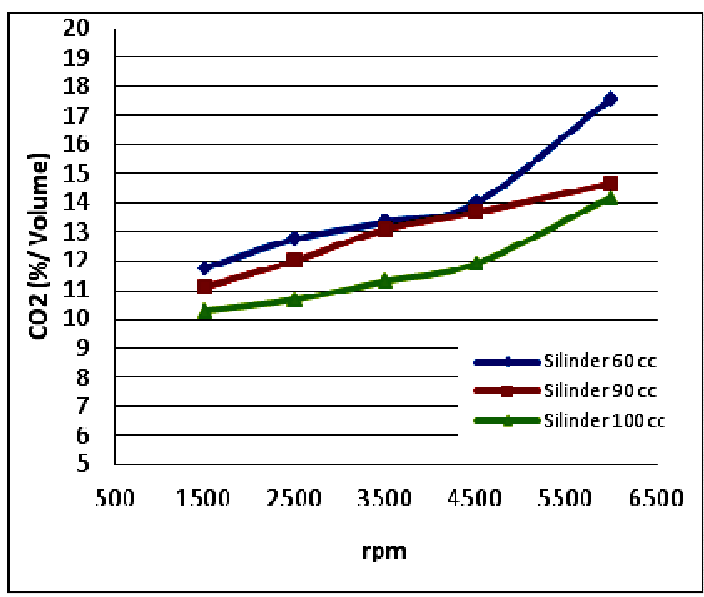

Gambar 9. Kadar emisi $\mathrm{CO}_{2}$ terhadap putaran pada berbagai variasi diameter piston pada transmisi 4

Dengan menurunnya volume displacement dan mengecilnya overlapping pada putaran 6000 rpm menyebabkan gas yang masuk kedalam ruang bakar semakin sedikit. Sedangkan pada silinder piston $100 \mathrm{cc}$ pada putaran $1500 \mathrm{rpm}$ transmisi 1 terjadi emisi $\mathrm{HC}$ yang tinggi, dikarenakan adanya pembebanan dari transmisi $\mathrm{N}$ (diam) ke transmisi 1 sehingga mesin membutuhkan bahan bakar yang lebih yang masuk kedalam ruang bakar belum dapat 
terbakar secara merata tetapi sudah terbuang bersama gas buang akibat pembakaran yang tidak sempurna.

Gambar 8 dan 9 menunjukkan emisi gas $\mathrm{CO}_{2}$ paling tinggi ada pada silinder piston $60 \mathrm{cc}$ pada transmisi 4 dan putaran $6000 \mathrm{rpm}$ dengan nilai $17,60 \%$ volume. Dan emisi paling rendah dengan nilai $\mathrm{CO}_{2}$ sebesar $8,37 \%$ volume tingkat transmisi 1 dan putaran mesin $1500 \mathrm{rpm}$ menggunakan silinder piston $100 \mathrm{cc}$.

Semakin tinggi emisi $\mathrm{CO}_{2}$ menunjukkan pembakaran yang terjadi semakin sempurna. Emisi $\mathrm{CO}_{2}$ berbanding terbalik dengan emisi $\mathrm{HC}$ dan $\mathrm{CO}$, yang artinya semakin tinggi emisi $\mathrm{CO}_{2}$ emisi $\mathrm{HC}$ dan $\mathrm{CO}$ yang terbentuk semakin rendah.Kondisi ini memperlihatkan semakin sedikit bahan bakar yang terbuang.Berdasarkan gambar 8 dan 9 emisi $\mathrm{CO}_{2}$ rata-rata mengalami peningkatan pada putaran tinggi, kondisi ini juga menunjukkan pada putaran tinggi pembakaran yang terjadi lebih sempurna.

Jika dibandingkan silinder piston 60 cc, 90 cc dan $100 \mathrm{cc}$, silinder piston $60 \mathrm{cc}$ menghasilkan emisi $\mathrm{CO}_{2}$ yang tinggi, hal ini disebabkan karena campuran udara dan bahan bakar yang dihisap semakin sedikit akibat penurunan diameter piston, semakin sedikit campuran udara dan bahan bakar yang masuk ke ruang bakar dan nyala api dari busi standar menyebabkan bahan bakar dan udara dapat terbakar secara merata sehingga emisi gas yang keluar hanya $\mathrm{CO}_{2}$.

\section{Pengaruh Variasi Diameter Terhadap Konsumsi Bahan Bakar (FC)}

Fuel Consumption (FC) merupakan tolak ukur untuk mengetahui jumlah bahan bakar yang dikonsumsi oleh mesin selama waktu tertentu. Setelah dilakukan penelitian terhadap FC dan didapatkan data dalam bentuk grafik.

Gambar 10,11 dan 12 menunjukkan konsumsi bahan bakar terendah dengan nilai 0,06 kg/jam tingkat transmisi 4 dengan silinder piston $60 \mathrm{cc}$ pada putaran $1500 \mathrm{rpm}$. Sedangkan konsumsi bahan bakar paling tinggi dengan nilai $0.65 \mathrm{~kg} / \mathrm{jam}$ tingkat transmisi 1 pada putaran $6000 \mathrm{rpm}$ pada silinder piston $100 \mathrm{cc}$.

Nilai konsumsi bahan bakar semakin meningkat seiring meningkatnya putaran mesin. Hal ini disebabkan karena pada putaran tinggi waktu yang dibutuhkan untuk satu siklus pembakaran menjadi lebih sedikit. Sehingga, pada putaran tinggi siklus pembakaran per satuan waktu akan terjadi lebih banyak jika dibandingkan dengan putaran rendah. Sehingga suplai bahan bakar yang masuk ke dalam silinder juga mengalami peningkatan.

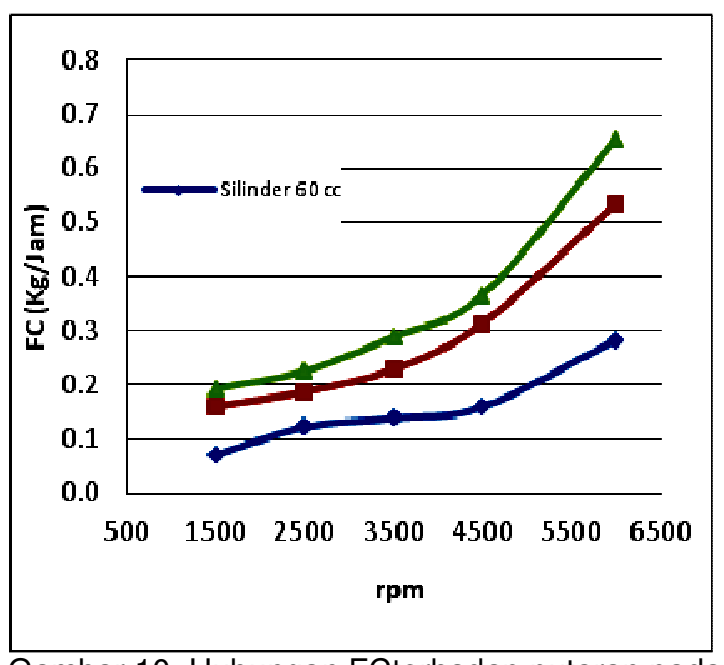

Gambar 10. Hubungan FCterhadap putaran pada berbagai variasi diameter piston pada transmisi normal

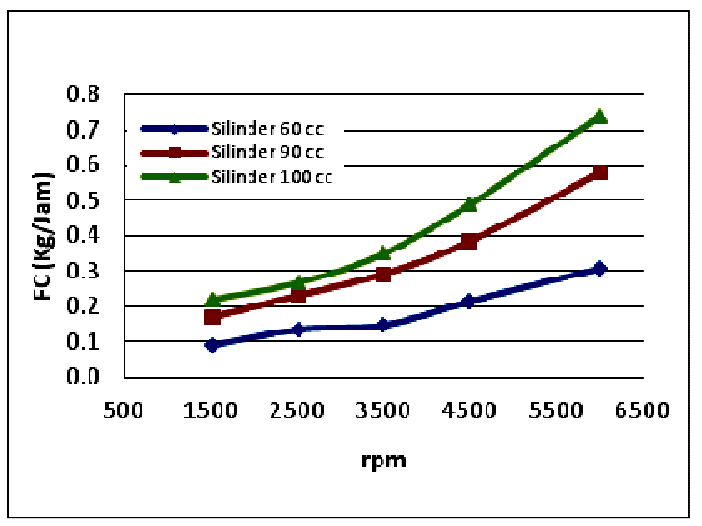

Gambar 11. Hubungan FCterhadap putaran pada berbagai variasi diameter piston pada transmisi 1

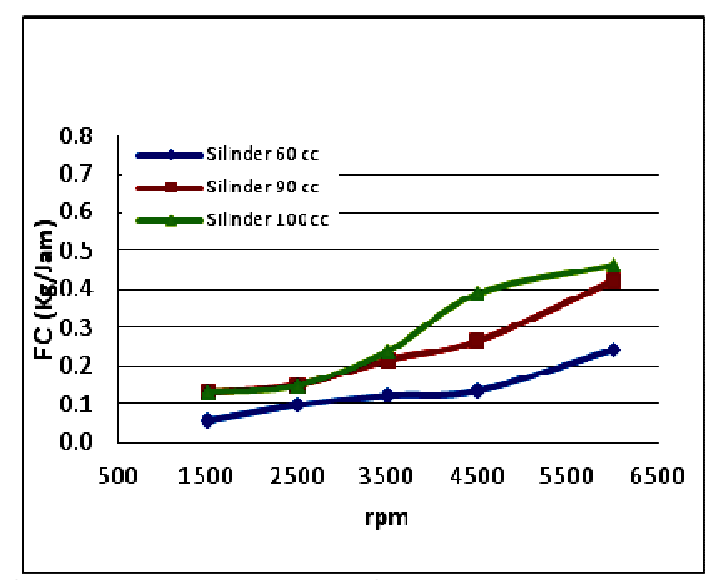

Gambar 12. Hubungan FCterhadap putaran pada berbagai variasi diameter piston pada transmisi normal

Semakin meningkatnya putaran mesin dan menurunnya volume displacementdari silinder 
100 cc ke selinder 60 cc akan sangat berpengaruh pada konsumsi bahan bakar .Hal ini disebabkan karena semakin kecil volume displacement maka campuran bahan bakar yang terhisap bersama udara kedalam slinder cenderung semakin sedikit.

\section{KESIMPULAN}

Dari serangkaian penelitian dan pembahasan mengenai pengaruh variasi volume silinder piston terhadap emisi gas buang mesin bensin empat langkah satu silinder, maka dapat ditarik kesimpulan sebagai berikut:

1. Semakin meningkatnya putaran mesin pada volume silinder piston $60 \mathrm{cc}$ dari putaran $1500,2500,3500$, 4500, hingga $6000 \mathrm{rpm}$ mengakibatkan kandungan $\mathrm{CO}$ semakin menurun.

2. Emisi $\mathrm{CO}$ terendah ada pada silinder piston 60 cc dengan nilai $0,31 \%$ pada putaran mesin $6000 \mathrm{rpm}$ transmisi 4. Sedangkan emisi CO tertinggi ada pada silinder piston 100 cc dengan nilai 4,64\% pada transmisi 1 putaran $1500 \mathrm{rpm}$.

3. Emisi $\mathrm{HC}$ terendah ada pada silinder piston $60 \mathrm{cc}$ pada putaran $6000 \mathrm{rpm}$ transmisi 4 sebesar 49,67 ppm, sedangkan emisi HC tertinggi pada silinder piston $100 \mathrm{cc}$ pada transmisi 1 putaran $1500 \mathrm{rpm}$ sebesar $514,33 \mathrm{ppm}$.

4. Emisi $\mathrm{CO}_{2}$ tertinggi pada silinder piston $60 \mathrm{cc}$ pada putaran $6000 \mathrm{rpm}$ transmisi 4 dengan nilai $17,60 \%$ volume, sedangkan emisi $\mathrm{CO}_{2}$ terendah pada silinder piston $100 \mathrm{CC}$ transmisi 1 pada putaran $1500 \mathrm{rpm}$ dengan nilai $8,37 \%$ volume.

5. Konsumsi bahan bakar (FC) terendah terdapat pada silinder piston 60 cc pada putaran $1500 \mathrm{rpm}$ transmisi 4 sebesar 0,06 $\mathrm{kg} / \mathrm{jam}$, sedangkan konsumsi bahan bakar tertinggi pada silinder piston $100 \mathrm{cc}$ pada transmisi 1 pada putaran $6000 \mathrm{rpm}$ dengan nilai $0,65 \mathrm{~kg} / \mathrm{jam}$.

\section{UCAPAN TERIMAKASIH}

Penulis pada

kesempatan ini mengucapkan terimakasih kepada semua pihak yang membantu baik berupa materi maupun pikiran sehingga penelitian dan paper ini terselesaikan.

\section{DAFTAR NOTASI}

$b \quad=$ volume pemakaian bahan bakar, $(\mathrm{ml})$.

$d \quad=$ diameter silinder $(\mathrm{cm})$

FC = fuel consumption (konsumsi bahan bakar, kg/jam).

I = panjang langkah $(\mathrm{cm})$

$n=$ jumlah silinder

$\mathrm{Ne} \quad=$ daya efektif (PS)

$N \quad=$ putaran mesin $(\mathrm{rpm})$

$T \quad=$ torsi (kgf.m)

$t \quad=$ waktu yang digunakan untuk mengkonsumsibahan bakar, (s).

$V d \quad=$ volume displacement $\left(\mathrm{cm}^{3}\right)$

$V_{f} \quad=$ berat spesifik bahan bakar, $\left(\mathrm{kg} / \mathrm{m}^{3}\right)$.

\section{DAFTAR PUSTAKA}

Anonymous, 2016, Peraturan Menteri Negara Lingkungan Hidup No.05/08/2006, Tentang ambang batas emisi gas buang kendaraan bermotor lama, http:// lh.surabaya.go.id/permen-05-2006

Arismunandar W., 1988, Motor bakar torak, ITB press.

Kartiko H., 2013, Pelatihan mekanik roda dua. http://kampungnews.com/2013/04/29/ptjasa-raharja-ntb-ntb-gelar-pelatihanmekanik-roda-dua .html

Sayoga I.M.A., 2011, Pengaruh masa pakai dan tingkat transmisi terhadap kadar emisi gas buang sepeda motor honda astrea grand, Dinamika Teknik Mesin Vol.1 No.1 hal.1-6.

Wijoyo C., 2008, Modifikasi volume silinder sepeda motor bebek $100 \mathrm{cc}$ menjadi 110 cc dengan kombinasi diameter piston dibanding langkah piston. Universitas Muhammadiyah Yogyakarta. 